\title{
Molecular Diversity and Genetic Relatedness of Candida albicans Isolates from Birds in Hungary
}

\author{
M. Domán (iD) L. Makrai · Gy. Lengyel · R. Kovács • L. Majoros • \\ K. Bányai
}

Received: 19 November 2020/Accepted: 10 January 2021 / Published online: 29 January 2021

(C) The Author(s) 2021

\begin{abstract}
The molecular epidemiology of Candida albicans infections in animals has been rarely studied. In this study, multilocus sequence typing was used to characterise the genetic diversity and population structure of 24 avian origin C. albicans isolates collected from different birds with candidiasis and compared to human isolates. Fourteen diploid sequence types (DSTs) including six new DSTs were determined. Cluster analysis revealed that isolates grouped into 8 clades. Bird isolates mainly belonged to minor clades and Clade 15 with DST 172 was the most common (11 isolates; 45.8\%). The remaining isolates were clustered into Clade 7 (5 isolates; 20.8\%), Clade 10 (4 isolates; $16.6 \%$ ), Clade 8 (2
\end{abstract}

Handling Editor: Rui Kano

M. Domán $(\bowtie) \cdot K$. Bányai

Centre for Agricultural Research, Institute for Veterinary Medical Research, P.O. Box 18, Budapest 1581, Hungary e-mail: doman.marianna@atk.hu

L. Makrai

Department of Microbiology and Infectious Diseases, University of Veterinary Medicine, Budapest, Hungary

Gy. Lengyel

Laboratory of Epidemiological Virology, Hungarian Defence Forces Military Medical Centre, Budapest, Hungary

R. Kovács · L. Majoros

Department of Medical Microbiology, Faculty of Medicine, University of Debrecen, Debrecen, Hungary isolates; $8.3 \%$ ), Clade 4 (1 isolate; $4.2 \%$ ) and Clade 16 (1 isolate; $4.2 \%$ ). Unweighted pair group method with arithmetic averages (UPGMA) and eBURST analyses showed that the genetic construction of avian origin $C$. albicans population is fairly diverse. Although species-specific lineages were not found, some degree of separation in the evolution of bird and human strains could be observed.

Keywords Candida albicans - Multilocus sequence typing $\cdot$ Birds $\cdot$ Clade $\cdot$ Genetic diversity

\section{Introduction}

Candidiasis is a sporadic fungal disease in livestock. C. albicans is the most prevalent fungal commensal of normal human and animal digestive microbiota and an environmental pollutant as well [1]. This yeast is also the major opportunistic pathogen responsible for both superficial and disseminated infections. The excessive use of broad-spectrum antibiotics, hormones and immunosuppressants in recent years contribute to the increasing prevalence of Candida infections [2]. In birds, contaminated food, beak abnormalities, tongue injuries, the stress of heavy flight or force-feeding predispose to oral or gastrointestinal candidiasis [3]. Since ingestion of contaminated food or drinking water is the usual route of transmission, contaminated environments (e.g. litter from poultry rearing 
facilities, areas contaminated with human waste) are potential sources for Candida exposure for birds. In addition, candidiasis is a zoonotic disease, therefore pathogens originating from different sources may be transferred to other host species [4].

C. albicans is predominantly diploid and displays high degree of genetic diversity across isolates, notably variations in the distribution of heterozygous polymorphisms along the genome. Genotyping strains within a microbial species on the basis of DNA sequences at multiple loci has greatly advanced study of the epidemiology and evolutionary phylogenetic of many fungal pathogens including $C$. albicans [5-8]. At the population level, molecular typing has revealed 19 clades of $C$. albicans strains so far [9, 10]. Some of these clades seem to exhibit geographical enrichment or phenotype specificities, however, no correlation between clade assignment and the ability of strains to cause different forms of infection or host specificity has been established yet $[11,12]$. Of note, $C$. albicans is member of the CTG clade that translate the CUG codon as serine rather than leucine. This flexibility of the genetic code along with several other genomic properties such as changes in ploidity, loss of heterozygosity and isochromosome formation contributes to their extraordinary adaptability to colonise a variety of host niches and wide range of natural environments, adapt to diverse selective pressures, as well as escape antifungal drugs [13-15].

Molecular epidemiologic studies have mainly focused on candidiasis in humans, but rarely in animals, thus in-depth investigations on molecular typing and evolutionary relationships are still lacking. To broaden our understanding on the population structure and genetic diversity of $C$. albicans strains in birds, we analysed 30 isolates recovered from animal and human hosts and investigated whether the genotype distribution related to their different source.

\section{Materials and Methods}

Specimen Collection

A total of 30 C. albicans isolates (one isolate from each bird) were examined in this study. Samples obtained from moulard and barbary ducks and geese diagnosed with oesophageal mycosis $(n=22)$, a falcon $(n=1)$, an ostrich $(n=1)$ and human patients $(n=6)$ (Table 1). Samples were plated on Sabouraud dextrose agar supplemented with chloramphenicol and incubated at $35^{\circ} \mathrm{C}$ for $48 \mathrm{~h}$. Human isolates were randomly selected and preliminary identified as $C$. albicans by Matrix-assisted laser desorption/ionization time of flight mass spectrometer at the University of Debrecen. All yeast isolates were subjected to molecular characterisation by sequencing of internal transcribed spacer (ITS) region of fungal rDNA [16].

Identification of yeasts by ITS sequencing

After culturing isolates for two days, genomic DNA from a single colony of each isolate (containing approx. $1 \times 10^{6}-5 \times 10^{6}$ yeast cells) was extracted using the Fungi/yeast genomic DNA extraction kit (Favorgen) in accordance with the manufacturer's instructions. DNA samples were stored at $-20{ }^{\circ} \mathrm{C}$ until analysis. Fungus-specific universal primers ITS 1 (5'-TCCGTAGGTGAACCTGCGG-3') and ITS4 (5'TCCTCCGCTTATTGATATGC- $3^{\prime}$ ) were used to amplify the entire ITS region [2, 17]. The final PCR mixture volume was $15 \mu \mathrm{l}$ containing $1 \mu \mathrm{l}$ fungal DNA, $2 \mu \mathrm{l} 10 \times$ DreamTaq buffer, $0.5 \mu \mathrm{l} \mathrm{dNTP}$ $(10 \mathrm{mM}), \quad 0.5 \mu \mathrm{l}$ forward and reverse primers (10 $\mu \mathrm{M}$ each), $0.1 \mu \mathrm{l}$ DreamTaq DNA polymerase (5 $\mathrm{U} / \mu \mathrm{l}$; Thermo Fisher Scientific) and $10.4 \mu \mathrm{l}$ distilled water. The condition was set up with an initial denaturation step at $95{ }^{\circ} \mathrm{C}$ for $3 \mathrm{~min}$, followed by 40 cycles of $95{ }^{\circ} \mathrm{C}$ for $30 \mathrm{~s}$, annealing at $50{ }^{\circ} \mathrm{C}$ for $30 \mathrm{~s}$, extension at $72{ }^{\circ} \mathrm{C}$ for $1 \mathrm{~min}$, and a final extension step at $72{ }^{\circ} \mathrm{C}$ for $10 \mathrm{~min}$. After the electrophoresis in $1 \%$ agarose gel stained with GelRed (Biotium), the PCR products were purified using Gel/PCR DNA fragments kit (Geneaid). Amplicons were sequenced on both strands using ITS1 and ITS4 primers with BigDye Terminator v3.1. cycle sequencing kit (Thermo Fisher Scientific) on an ABI Prism 3130 Genetic Analyzer (Applied Biosystems). Sequences were edited and assembled using Mega 6 software (https://www. megasoftware.net/) then species level identification was carried out by the BLAST sequence analysis tool (https://blast.ncbi.nlm.nih.gov/Blast.cgi). Generated nucleotide sequences were deposited in GenBank under the following accession numbers: MT136511MT136532 and MT478010-MT478017. 
Table 1 Origin of C. albicans isolates and MLST genotypes involved in the study

\begin{tabular}{|c|c|c|c|c|c|c|c|c|c|c|c|}
\hline \multirow[t]{2}{*}{ Host } & \multirow[t]{2}{*}{ Isolate number } & \multirow[t]{2}{*}{ Origin } & \multicolumn{7}{|c|}{ MLST loci } & \multirow[t]{2}{*}{ DST } & \multirow[t]{2}{*}{$\mathrm{CC}$} \\
\hline & & & AATla & $A C C 1$ & $A D P 1$ & $M P I b$ & SYA1 & VPS13 & $Z W F 1 b$ & & \\
\hline goose & ML-1 & Oesophagus & $55^{*}$ & 14 & 4 & 3 & 6 & 45 & 15 & 365 & 3 \\
\hline goose & ML-2 & Oesophagus & 6 & 3 & 37 & 2 & 38 & 116 & 12 & 482 & 16 \\
\hline duck & ML-3 & Oesophagus & 13 & 3 & 4 & 6 & 34 & 20 & 18 & 172 & 43 \\
\hline duck & ML-4 & Oesophagus & 13 & 3 & 4 & 6 & 34 & 20 & 18 & 172 & 43 \\
\hline goose & ML-5 & Oesophagus & 74 & 7 & 16 & 7 & 13 & 19 & 296 & 3599 & 17 \\
\hline goose & Om-1 & Oesophagus & 74 & 7 & 16 & 7 & 13 & 19 & 296 & 3599 & 17 \\
\hline goose & Om-2 & Oesophagus & 13 & 3 & 4 & 6 & 34 & 20 & 18 & 172 & 43 \\
\hline duck & Om-7 & Oesophagus & 13 & 3 & 4 & 6 & 34 & 20 & 18 & 172 & 43 \\
\hline duck & Om-8 & Oesophagus & 74 & 7 & 16 & 7 & 13 & 165 & 14 & 3595 & 17 \\
\hline goose & Om-11 & Oesophagus & 6 & 3 & 37 & 2 & 38 & 46 & 12 & 840 & 16 \\
\hline goose & Om-12 & Oesophagus & 6 & 3 & 37 & 2 & 38 & 46 & 12 & 840 & 16 \\
\hline goose & Om-13 & Oesophagus & 74 & 7 & 16 & 7 & 13 & 19 & 296 & 3599 & 17 \\
\hline goose & Om-14 & Oesophagus & 6 & 3 & 37 & 2 & 38 & 46 & 12 & 840 & 16 \\
\hline duck & Om-16 & Oesophagus & 70 & 14 & 8 & 4 & 2 & 10 & 8 & 725 & 1 \\
\hline duck & Om-17 & Oesophagus & 55 & 14 & 4 & 3 & 6 & 45 & 15 & 365 & 3 \\
\hline duck & Om-18 & Oesophagus & 13 & 3 & 4 & 6 & 34 & 20 & 18 & 172 & 43 \\
\hline goose & Om-19 & Oesophagus & 13 & 3 & 4 & 6 & 34 & 20 & 18 & 172 & 43 \\
\hline goose & Om-29 & Oesophagus & 13 & 3 & 4 & 6 & 34 & 20 & 18 & 172 & 43 \\
\hline goose & Om-31 & Oesophagus & 13 & 3 & 4 & 6 & 34 & 20 & 18 & 172 & 43 \\
\hline duck & Om-34 & Oesophagus & 13 & 3 & 4 & 6 & 34 & 20 & 18 & 172 & 43 \\
\hline duck & Om-36 & Oesophagus & 13 & 3 & 4 & 6 & 34 & 20 & 18 & 172 & 43 \\
\hline duck & Om-42 & Oesophagus & 13 & 3 & 4 & 6 & 34 & 20 & 18 & 172 & 43 \\
\hline falcon & 12086 & Pharynx & 53 & 31 & 10 & 36 & 83 & 113 & 111 & 1019 & 13 \\
\hline ostrich & Im-12 & Intestine & 6 & 3 & 37 & 2 & 38 & 50 & 12 & 3598 & 16 \\
\hline human & 22491 & Decubitus & 2 & 5 & 5 & 9 & 2 & 6 & 5 & 79 & 0 \\
\hline human & 7652 & Wound & 70 & 14 & 8 & 4 & 2 & 3 & 8 & 623 & 1 \\
\hline human & 14362 & Blood & 6 & 3 & 37 & 2 & 38 & 50 & 12 & 3598 & 16 \\
\hline human & 27700 & Cervix & 21 & 114 & 21 & 19 & 30 & 307 & 22 & 3600 & $\mathrm{~S}$ \\
\hline human & 38002 & Cervix & 105 & 3 & 5 & 2 & 2 & 24 & 5 & 3597 & 0 \\
\hline human & 43279 & Pharynx & 70 & 7 & 8 & 4 & 7 & 10 & 22 & 3596 & 1 \\
\hline
\end{tabular}

DST Diploid sequence type assigned by $C$. albicans MLST database based on allelic profiles (allele number combinations)

*Allele type; $C C$ Clonal Complex determined by eBURST; $S$ singleton

Multilocus Sequence Typing (MLST) of $C$. albicans Isolates

The MLST scheme employed for $C$. albicans genotyping was based on partial amplification and sequencing of seven housekeeping genes (AATla, ACCl, $A D P 1, M P I b, S Y A 1, V P S 13$ and $Z W F 1 b)$ according to a previously published method [5]. Seven independent PCR amplifications were performed for each isolate.
The primer sets and their amplicon lengths were described in detail elsewhere [5, 18]. Experimental conditions used in PCRs and Sanger sequencing were the same as mentioned above.

Heterozygosity was identified by the presence of two peaks at the same polymorphic loci on both strands and the consensus sequences of seven loci of all isolates were defined. For each gene, distinct alleles and diploid sequence types (DSTs) were identified and 
numbered by comparing the sequences with those available in the C. albicans MLST database (https:// pubmlst.org/organisms/candida-albicans). Novel alleles and allelic combinations (new DTSs) together with sequence chromatograms were submitted to the central MLST database where new numbers were assigned by the curator.

Phylogenetic and Population Structure Analysis

Nucleotide sequences were modified as described by Tavanti et al. 2005 to label homozygous and heterozygous sites in order to allow the cluster analysis of diploid sequence data [6]. Relationship among concatenated sequences of the seven loci of each isolate were determined using unweighted pair group method with arithmetic averages (UPGMA) algorithm with p-distance model in Mega 6 software. A bootstrap of 1000 replications was used for the construction $[9,19]$. MLST clonal complexes (CC) and their founders were predicted by goeBURST algorithm (http://www. phyloviz.net/goeburst/) to analyse population structure and evolutionary relationships between isolates. A CC was defined to contain at least two DSTs sharing any 6 of the 7 MLST alleles (single-locus variant analysis). DSTs that could not be assigned to any group were called singletons.

\section{Results}

All isolates were identified as $C$. albicans by sequencing the internal transcribed spacer region. Partial DNA sequences of the coding regions of the multiple genetic loci included in MLST scheme were concatenated to generate a dataset of $2883 \mathrm{bp}$ for each examined isolate. A total of 57 different alleles were identified among the 30 genotyped $C$. albicans isolates. The VPS13 locus generated the most number of alleles $(n=12)$, while ACCl locus produced the least $(n=6)$. Overall, 66 nucleotide sites were found to be variable among all sequenced loci. Similarly, the VPS13 locus produced the highest number of polymorphic sites $(n=12)$, while ACCl displayed the lowest $(n=5)$ (Table 2). Among the alleles, three new alleles were determined in ACC1, VPS13 and ZWF $1 b$ loci, respectively, and each were added to the MLST database.

Fourteen unique DSTs were obtained with the combination of all seven allele numbers. Six of the 14 DSTs were new MLST genotypes (DST numbers: 3595-3600). Of note, 4 of the 6 new DSTs were recovered from human patients, whereas the majority of animal isolates belonged to previously described MLST genotypes $(19 / 24 ; 79 \%)$ (Table 1$)$. In order to reveal the phylogenetic relationship between isolates, we performed cluster analysis of isolates included in the present study and two reference DSTs from each previously assigned clades determined by UPGMA analysis [10]. The 30 C. albicans isolates grouped into 8 clades. The most prevalent genotype of bird isolates was DST $172(11 / 24 ; 45.8 \%)$ which clustered into Clade 15. Clade 7 was the second most common clade $(5 / 24 ; 20.8 \%)$, followed by Clade $10(4 / 24 ; 16.6 \%)$, Clade $8(2 / 24 ; 8.3 \%)$, Clade $4(1 / 24 ; 4.2 \%)$ and Clade $16(1 / 24 ; 4.2 \%)$. Human isolates grouped into Clade 1

Table 2 Characteristics of the seven examined MLST housekeeping genes

\begin{tabular}{|c|c|c|c|c|}
\hline Locus & $\begin{array}{l}\text { Sequenced fragment size } \\
\text { (bp) }\end{array}$ & $\begin{array}{l}\text { Number of } \\
\text { alleles }\end{array}$ & $\begin{array}{l}\text { Number of polymorphic } \\
\text { sites }\end{array}$ & Nucleotide position \\
\hline AATla & 373 & 8 & 7 & $7,28,40,70,89,124,325$ \\
\hline$A C C 1$ & 407 & 6 & 5 & $8,90,211,281,317$ \\
\hline$A D P 1$ & 443 & 7 & 11 & $17,35,40,46,109,125,166,205,215,225,232$ \\
\hline$M P I b$ & 375 & 8 & 11 & $21,27,34,36,66,72,88,234,237,276,289$ \\
\hline SYA1 & 391 & 7 & 9 & $1,25,61,100,142,160,185,307,351$ \\
\hline VPS13 & 403 & 12 & 12 & $\begin{array}{l}33,49,134,212,217,241,281,320,322,328 \\
\quad 370,375\end{array}$ \\
\hline$Z W F 1 b$ & 491 & 9 & 11 & $23,31,43,49,55,262,274,337,379,439,482$ \\
\hline Total & 2883 & 57 & 66 & - \\
\hline
\end{tabular}


Fig. 1 Evolutionary relationship of 30 Candida albicans isolates recovered in the study with reference isolates representing the MLST clades. The dendrogram was constructed by UPGMA analysis with p-distance method based on concatenated sequences of the seven loci. Black diamonds indicate isolates originated from animal source, while human isolates are highlighted with red diamonds. (Color figure online)

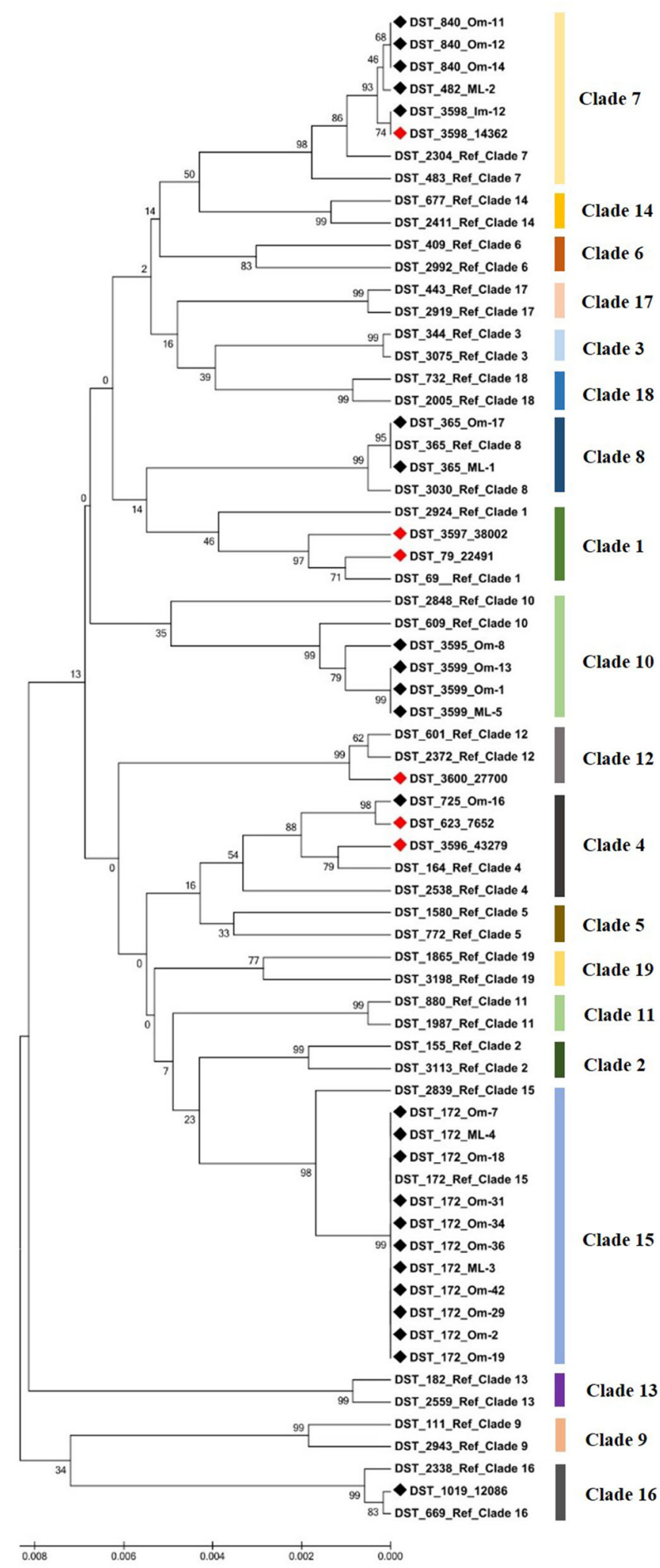




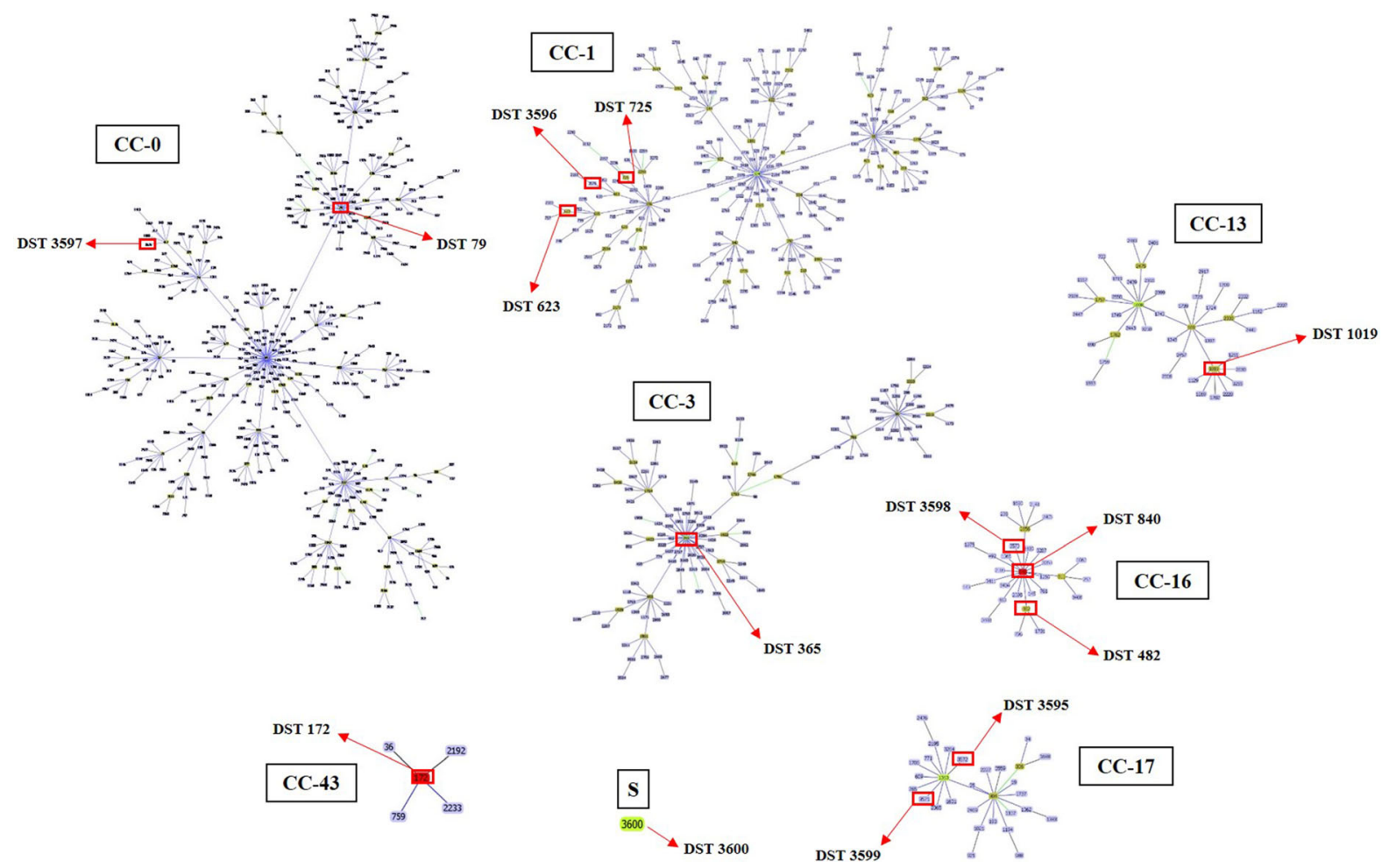

Fig. 2 eBURST snapshot for Candida albicans diploid sequence types (DSTs) available in the MLST database. The illustration shows only those clonal complexes (CCs), which

$(2 / 6 ; 33.3 \%)$, Clade $4(2 / 6 ; 33.3 \%)$, Clade $7(1 / 6$; $16.6 \%)$ and Clade $12(1 / 6 ; 16.6 \%)$. Interestingly, one waterfowl isolate (Om-16) and one human isolate (7652) was genetically closely related (Fig. 1). Moreover, the Im-12 isolate derived from ostrich and the human isolate 14362 shared the same DST, confirming that there is no host specificity of C. albicans strains in certain genotypes (Table 1, Fig. 1).

The allelic profiles of Hungarian C. albicans strains were compared with those deposited in the MLST database. Analysis of the genotypic relationship of strains using goeBURST algorithm yielded 3600 DSTs that were grouped into $156 \mathrm{CCs}$ and 1113 singletons. CCs generated by goeBURST were arbitrarily numbered starting from 0 (for the $\mathrm{CC}$ with most DSTs). Clades determined by UPGMA corresponded well to the eBURST groups. The 30 isolates in this study were placed in $7 \mathrm{CCs}$, while one isolate was singleton (Table 1, Fig. 2). CC-43 contained 11 isolates of genotype DST 172, which was the putative founder of the group. DST 365 and DST 840 were also the predicted clonal founders of CC-3 and CC-16, include Hungarian isolates (these are marked with red rectangles). A singleton (i.e. DST that could not be assigned to any group) is indicated with letter ' $\mathrm{S}$ '. (Color figure online)

respectively. The most abundant groups (CC-0, CC-1, CC-3) involved 7 isolates (3 bird and 4 human), whereas the remaining isolates were clustered to smaller groups as CC-13 $(n=1), \mathrm{CC}-16(n=6)$ and CC-17 $(n=4)$. The newly identified animal isolates typed DST 3595 and DST 3599 belonged to CC-17 and both of them putatively evolved from DST 1363 group founder, which was identified from human samples according to the public database. The identical DST found among bird and human isolates, DST 3598 was assigned to CC-16 and probably developed from DST 840 group founder, like the closely related DST 482 (Fig. 2).

\section{Discussion}

The MLST technique has contributed significantly to the understanding of the epidemiological and evolutionary relationships of different $C$. albicans strains due to its high discriminatory power [20]. We characterised the genetic diversity and population 
structure of $C$. albicans isolated from birds by the MLST method and assessed the genotypic distribution between hosts by involving human isolates as well. Based on nucleotide sequence variations in the seven housekeeping genes, 21 isolates were assigned eight previously known DSTs and nine isolates were assigned six new DSTs. Concerning human isolates the five major clades assigned by UPGMA (Clade 1, 2 , 3,4 and 11) have proved the most consistent over several years of rapid expansion of the MLST global database [7]. In our analysis, two human isolates (DST 623 and DST 3596) were assigned to Clade 4 and one bird isolate (DST 725). Two human isolates (DST 79 and DST 3597) clustered to Clade 1, while no isolate was found in Clade 2 and 11 suggesting that $C$. albicans isolates originating from animal source rather belong to minor clades. Furthermore, although Clade 1 is a major clade worldwide, it contains only a few isolates from animals raising the possibility that Clade 1 isolates may be better adapted to colonise and infect humans [21, 22].

MLST analysis revealed that isolates in the same eBURST clonal complexes were grouped together in the respective clades determined by UPGMA clustering, which was consistent with former observations $[2,23,24]$. None of the known DSTs found in our study were identified exclusively from animals (https://pubmlst.org/organisms/candida-albicans).

New DSTs were recovered mainly from humans, suggesting that $C$. albicans is exposed to higher selective pressure in this host, which along with hospital environment may promote a more rapid evolution of this yeast. Taking the results into consideration, similarly to previous conclusion $[11,22]$ C. albicans subpopulations from birds and humans presumably develop relatively independently, while still maintaining some common features enabling the transfer of several genotypes between humans and animals.

To the best of our knowledge, the present study in the first to report molecular typing by MLST method and phylogenetic analysis of avian C. albicans isolated in Hungary. The low sample size and the lack of MLST genotyping of additional isolates from humans and other animals prevented us to perform extensive country-wide comparison of field isolates. However, we have gained insight into the molecular epidemiology and population evolution of $C$. albicans in birds. Considering that isolates from distinct genotypes or clades may have different phenotypes in terms of virulence, pathogenesis and drug resistance, our results provide good basis for further genome-based analyses.

Author Contributions Marianna Domán and Krisztián Bányai designed the study. László Makrai, Renátó Kovács and László Majoros provided samples and data. Marianna Domán performed experiments and data analysis. György Lengyel performed Sanger sequencing. Marianna Domán and Krisztián Bányai prepared the first manuscript draft. All authors read and approved the manuscript.

Funding Open Access funding provided by ELKH Centre for Agricultural Research. Project No. PD 128617 has been implemented with the support provided from the National Research, Development and Innovation Office of Hungary, financed under the postdoctoral excellence programme (PD_18) funding scheme. Additional funding was obtained from the Momentum program (awarded by the Hungarian Academy of Sciences).

Data Availability The ITS sequence data are available in the GenBank with accession numbers MT136511-MT136532 and MT478010-MT478017. Allele sequences and DST numbers of Hungarian C. albicans isolates are available in MLST database (https://pubmlst.org/organisms/candida-albicans).

\section{Compliance with Ethical Standards}

Conflict of interest The authors report no conflicts of interest. The authors alone are responsible for the content and writing of this paper.

Ethics Approval The authors confirm that no ethical approval was required. This work was carried out with diagnostic samples and no animal experimentation was conducted.

Open Access This article is licensed under a Creative Commons Attribution 4.0 International License, which permits use, sharing, adaptation, distribution and reproduction in any medium or format, as long as you give appropriate credit to the original author(s) and the source, provide a link to the Creative Commons licence, and indicate if changes were made. The images or other third party material in this article are included in the article's Creative Commons licence, unless indicated otherwise in a credit line to the material. If material is not included in the article's Creative Commons licence and your intended use is not permitted by statutory regulation or exceeds the permitted use, you will need to obtain permission directly from the copyright holder. To view a copy of this licence, visit http://creativecommons.org/licenses/by/4.0/.

\section{References}

1. Rosario Medina I, Román Fuentes L, Batista Arteaga M, Real Valcárcel F, Acosta Arbelo F, Padilla Del Castillo D, 
Déniz Suárez S, Ferrer Quintana O, Vega Gutiérrez B, Silva Sergent F, Acosta-Hernández B. Pigeons and their droppings as reservoirs of Candida and other zoonotic yeasts. Rev Iberoam Micol. 2017;34(4):211-4.

2. Liu J, Liu H, Yan J, Liu N, Zhang H, Zhao C, Liu Y. Molecular typing and genetic relatedness of 72 clinical Candida albicans isolates from poultry. Vet Microbiol. 2018;214:36-43.

3. Kunkle RA. Fungal infections. In: Saif YM, Barnes HJ, Glisson JR, Fadly AM, McDougald LR, Swayne DE, editors. Diseases of poultry. 11th ed. Ames: Iowa State Press; 2003. p. 901.

4. Mugale M, Bhat AA, Gavhane DS, Bhat SA. Outbreaks of thrush in pigeons in Punjab State of India. Comp Clin Path. 2015;24(3):635-8.

5. Bougnoux ME, Tavanti A, Bouchier C, Gow NA, Magnier A, Davidson AD, Maiden MC, D'Enfert C, Odds FC. Collaborative consensus for optimized multilocus sequence typing of Candida albicans. J Clin Microbiol. 2003;41:5265-6.

6. Tavanti A, Davidson AD, Fordyce MJ, Gow NA, Maiden MC, Odds FC. Population structure and properties of Candida albicans, as determined by multilocus sequence typing. J Clin Microbiol. 2005;43:5601-13.

7. Odds FC. Molecular phylogenetics and epidemiology of Candida albicans. Future Microbiol. 2010;5(1):67-79.

8. Sitterlé E, Maufrais C, Sertour N, Palayret M, d'Enfert C, Bougnoux ME. Within-host genomic diversity of Candida albicans in healthy carriers. Sci Rep. 2019;9(1):2563.

9. Shin JH, Bougnoux ME, D'Enfert C, Kim SH, Moon CJ, Joo MY, Lee K, Kim M-N, Lee HS, Shin MG, Suh SP, Ryang DW. Genetic diversity among Korean Candida albicans bloodstream isolates: assessment by multilocus sequence typing and restriction endonuclease analysis of genomic DNA by use of BssHII. J Clin Microbiol. 2011;49(7):2572-7.

10. Gong YB, Jin B, Qi H, Zhang R, Zhang XY, Yuan P, Zhao TX, Geng XH, Zhang M, Zheng JL. Multilocus sequence typing of Candida albicans isolates from the oral cavities of patients undergoing haemodialysis. Sci Rep. 2018;8(1):16413.

11. Edelmann A, Krüger M, Schmid J. Genetic relationship between human and animal isolates of Candida albicans. J Clin Microbiol. 2005;43(12):6164-6.

12. Odds FC, Bougnoux ME, Shaw DJ, Bain JM, Davidson AD, Diogo D, Jacobsen MD, Lecomte M, Li SY, Tavanti A, Maiden MC, Gow NA, d'Enfert C. Molecular phylogenetics of Candida albicans. Eukaryot Cell. 2007;6:1041-52.

13. Hirakawa MP, Martinez DA, Sakthikumar S, Anderson MZ, Berlin A, Gujja S, Zeng Q, Zisson E, Wang JM, Greenberg JM, Berman J, Bennett RJ, Cuomo CA. Genetic and phenotypic intra-species variation in Candida albicans. Genome Res. 2015;25:413-25.
14. Ene IV, Bennett RJ, Anderson MZ. Mechanisms of genome evolution in Candida albicans. Curr Opin Microbiol. 2019;52:47-54.

15. Scordino F, Giuffrè L, Felice MR, Orlando MG, Medici MA, Marino Merlo F, Romeo O. Genetic diversity of Candida albicans isolates recovered from hospital environments and patients with severe acquired brain injuries. Infect Genet Evol. 2019;76:104068.

16. Schoch CL, Seifert KA, Huhndorf S, Robert V, Spouge JL, Levesque CA, Chen W. Fungal barcoding consortium; fungal barcoding consortium author list. Nuclear ribosomal internal transcribed spacer (ITS) region as a universal DNA barcode marker for Fungi. Proc Natl Acad Sci. 2012;109(16):6241-6.

17. Fujita SI, Senda Y, Nakaguchi S, Hashimoto T. Multiplex PCR using internal transcribed spacer 1 and 2 regions for rapid detection and identification of yeast strains. J Clin Microbiol. 2001;39:3617-22.

18. Tavanti A, Gow NA, Senesi S, Maiden MC, Odds FC. Optimization and validation of multilocus sequence typing for Candida albicans. J Clin Microbiol. 2003;41:3765-76.

19. Pham LTT, Pharkjaksu S, Chongtrakool P, Suwannakarn K, Ngamskulrungroj P. A predominance of Clade 17 Candida albicans isolated from hemocultures in a tertiary care hospital in Thailand. Front Microbiol. 2019;10:1194.

20. Maiden MC, Bygraves JA, Feil E, Morelli G, Russell JE, Urwin R, Zhang Q, Zhou J, Zurth K, Caugant DA, Feavers IM, Achtman M, Spratt BG. Multilocus sequence typing: a portable approach to the identification of clones within populations of pathogenic microorganisms. Proc Natl Acad Sci U S A. 1998;95(6):3140-5.

21. Jacobsen MD, Bougnoux ME, d'Enfert C, Odds FC. Multilocus sequence typing of Candida albicans isolates from animals. Res Microbiol. 2008;159(6):436-40.

22. Wrobel L, Whittington JK, Pujol C, Oh SH, Ruiz MO, Pfaller MA, Diekema DJ, Soll DR, Hoyer LL. Molecular phylogenetic analysis of a geographically and temporally matched set of Candida albicans isolates from humans and nonmigratory wildlife in central Illinois. Eukaryot Cell. 2008;7(9):1475-86.

23. Odds FC, Jacobsen MD. Multilocus sequence typing of pathogenic Candida species. Eukaryot Cell. 2008;7:1075-84.

24. Wang SH, Shen M, Lin HC, Sun PL, Lo HJ, Lu JJ. Molecular epidemiology of invasive Candida albicans at a tertiary hospital in northern Taiwan from 2003 to 2011. Med Mycol. 2015;53(8):828-36.

Publisher's Note Springer Nature remains neutral with regard to jurisdictional claims in published maps and institutional affiliations. 